\title{
A bright future ahead for Journal of Molecular Endocrinology
}

\section{Outgoing Editor-in-Chief}

Over the last 3 years, our two leading journals of endocrine basic science, Journal of Endocrinology and Journal of Molecular Endocrinology, have undertaken an unusual and possibly unique experiment in scientific publishing. Concerned with the perception that the precise scientific remit of these journals had become indistinct, we took the step of creating a single expert editorial board to oversee both journals and to define their remit with greater clarity. This structure provided the additional option of re-allocating manuscripts between the journals so as to optimize their fit. At the same time, we have sought to expand the international perspective of the journals, in part by expanding the geographical coverage of the editorial board to reflect the developing spread of endocrine excellence. Furthermore, we have modernized the journal format, bringing in varied and attractive journal covers, more contemporary fonts and page sizes. Now, as I come to the end of my term as editor-in-chief of the joint board, it seems a good time to review the effectiveness of this experiment.

Journal submissions and acceptances have increased by $50 \%$ over this period. A significant part of this increase has been from less traditional endocrine scientific communities such as those in Central and South America, China, and the Far East, where the evidence shows that excellent endocrine basic science is underway. This expansion is in part the result of a highly engaged and active editorial board who, in addition to handling manuscripts, have acted as great ambassadors for the journals around the world. Evidence for their effectiveness has been the adoption of the journals as the official basic endocrine science journals of the Endocrine Society of Australia.

At heart, these journals are the journals of the Society for Endocrinology, and we take the requirement to serve that organization seriously. In addition to the significant financial benefits, I believe the journals have a key role in supporting, developing and recognizing excellent endocrine science. Thus we have introduced a now regular series on successful scientific publishing at Society for Endocrinology meetings as well as at other meetings around the world, including Australia and China. We reward excellent endocrinologists publishing in the journals with our annual prizes, and increasingly support and sponsor scientific sessions in significant meetings. We have also initiated a series of special issues commemorating major achievements in endocrinology, including those on '20 Years of Leptin', the anniversary of Harris's monograph on Neuroendocrinology, and, next year, the 60th anniversary of the sequencing of adrenocorticotropic hormone and the discovery of pro-opiomelanocortin.

In practical terms, the journals are now running as efficiently as ever. This is due to the outstanding and highly professional editorial office support. The ethical dilemmas of scientific publishing play an increasing part in managing any journal and Journal of Endocrinology and Journal of Molecular Endocrinology are no exception, but office support and advice in this area have been excellent.

My successor as editor-in-chief is Sofianos Andrikopoulos. I am delighted that he has agreed to devote his considerable energies and vision to the journals and he will bring huge experience, gained in part as deputy editor, to this role. I have great confidence that he will be able to steer the journals forward at a time in which the challenges to scientific publishing have never been greater. I wish him well in the knowledge that the journals are in great hands!

Adrian Clark

\section{Incoming Editor-in-Chief}

I am honored, humbled, and excited that I have been entrusted with the stewardship of the Journal of Endocrinology and Journal of Molecular Endocrinology by the Society for Endocrinology. Many of you may know that I have been involved with these journals for a number of years, progressing from reviewer to senior editor and deputy editor-in-chief, and finally the top job. To say that I have 'big shoes to fill' following on from Adrian Clark is a gross understatement given the extraordinary work and success that he has had in overseeing the merger of the two editorial boards as well as making both journals truly international from an editorial-board and manuscriptsubmission point of view. Adrian's vision has been justly

This editorial has been simultaneously published in the Journal of Endocrinology (doi:10.1530/JOE-15-0410) and the Journal of Molecular Endocrinology

(doi:10.1530/JME-15-8236) oaded from Bioscientifica.com at 04/26/2023 05:19:53AM 
rewarded by significant increases in manuscript submissions and acceptances and, more importantly, increases in citation numbers and impact factors of both journals.

So what does the future hold for the Journal of Endocrinology and Journal of Molecular Endocrinology? There is no doubt that scientific publishing is under siege from new online publishers claiming expertise and promising a quick and fair reviewing process, sometimes at a hefty price. This may well attract and reduce submissions to more traditional journals like ours. In this competitive landscape, we must ensure that we uphold the reputation we have built over the past 76 years as a leader in publishing research articles in endocrinology. This will be achieved by maintaining our high reviewing standards and continuing to accept exciting and innovative research that advances our knowledge and understanding of endocrinology. We have an obligation to provide this service to our valued readership, and I will work hard to ensure that this expectation is fulfilled. To this end,
I am supported by the knowledgeable and experienced Prof. Colin Farquharson as deputy editor-in-chief, who is well known to the members of the Society for Endocrinology and fortunate to inherit a dynamic, engaged and professional international editorial board. With the support and guidance of Bioscientifica and Head of Publishing, we will continue to innovate and advance both journals such that they continue to be at the forefront of researchers' list for submission of their valuable studies.

It has not escaped me that I will be the first editor-inchief not to be based in the UK in the 76-year history of the Journal of Endocrinology. This again highlights the truly global reach and relevance of both the Journal of Endocrinology and Journal of Molecular Endocrinology and is indicative of fertile and exciting times ahead. I am thrilled that I will have the opportunity to contribute and be part of this journey towards continued success.

\section{Sof Andrikopoulos}

